\title{
Retraction of: Electronic Clinical Decision Support Intervention to Increase Hepatitis C Screening and Linkage to Care Among Baby Boomers in Urban Safety Net Health Systems, by Armstrong, et al. (Popul Health Manag; 2019 Oct 8. doi: 10.1089/pop.2019.0105. [Epub ahead of print]
}

The article entitled, "Electronic Clinical Decision Support Intervention to Increase Hepatitis C Screening and Linkage to Care Among Baby Boomers in Urban Safety Net Health Systems," by Armstrong et al., published online ahead of print (2019 Oct 8) in Population Health Management [doi: 10.1089/pop.2019.0105], requires a retraction due to duplicate publication in the Journal of Community Medicine \& Health Education (JCMHE) in February of 2019, and then in Population Health Management in October of 2019.

As it is against the standard protocols of peer review to publish original research in two different journals, Population Health Management is officially retracting the article from its literature.

Population Health Management is dedicated to adhering to the policies and best practices of scientific publishing and the community it serves. 